\title{
Necrotizing Activity of Verticillium dahliae and Fusarium oxysporum f. sp. vasinfectum Endopolygalacturonases in Cotton
}

Nana Liu, Xiaowen Ma, Yun Sun, and Yuxia Hou, College of Science, China Agricultural University, Beijing 100193, P. R. China; and Xueyan Zhang and Fuguang Li, State Key Laboratory of Cotton Biology, Institute of Cotton Research of the Chinese Academy of Agricultural Sciences, Anyang 455000, P. R. China

\begin{abstract}
Polygalacturonase (PG), which digests the pectin of plant cell walls, contributes to pathogenicity of fungi in plants. To explore the role of PG in pathogenicity of the fungal cotton pathogens Verticillium dahliae and Fusarium oxysporum f. sp. vasinfectum, VDPG1 and FOVPG1 were cloned and their expression in different cotton (Gossypium hirsutum) cultivars and media was analyzed. VDPG1 and FOVPG1 were strongly upregulated during infection. Purified VDPG1 and FOVPG1 play important roles in the symptom development of both resistant and susceptible cotton. Moreover, after inoculation with purified PGs, the hydroxyproline

content of the cell walls increased in cotton seedlings, with resistant cultivar seedlings showing significantly higher hydroxyproline content than seedlings of the susceptible cultivar. PG gene expression analysis in different media showed that both PG genes were induced in pectin medium but not in glucose medium. This study highlighted the role of VDPG1 and FOVPG1 in pathogenicity and virulence, which were detected in fungus-inoculated cotton, suggesting that PGs play an important role in the pathogenicity of $V$. dahliae and $F$. oxysporum f. sp. vasinfectum.
\end{abstract}

Verticillium and Fusarium wilt, two important fungal diseases of cotton (Gossypium hirsutum L.), have a profound impact on agriculture, causing enormous economic losses (Heale 1988; Zambounis et al. 2007). Polygalacturonase (PG) is a type of cell wall-binding protein that hydrolyzes pectin, thus being one of the major enzymes involved in the degradation of plant skeleton structure (de Vries and Visser 2001). PG was first obtained in vitro from cell walls of pathogenic fungi and occurs in bacteria, fungi, and plants. Based on the method of degradation of galacturonic acid, PG can be divided into endo-PG $(\mathrm{EC} 3 \cdot 2 \cdot 1 \cdot 15)$ and exo-PG $(\mathrm{EC} 3 \cdot 2 \cdot 1 \cdot 67)$. Endo-PG randomly digests the $\alpha-1,4$-glycosidic bond of the polygalacturonic acid (PGA), producing galacturonic acid oligomers with a polymerization degree of 10 to 14 (Cook et al. 1999). Substrate specificity of endo$\mathrm{PG}$ is stronger and this PG plays an important role in fungal pathogenicity (Reymond-Cotton et al. 1996).

The endo-PG gene, which has been identified in many pathogenic fungi and oomycetes, belongs to a multigene family, along with the endo-PGs of Botrytis cinerea (DellaPenna and Bennett 1988), Phytophthora cinnamomi (Götesson et al. 2002), and Sclerotinia sclerotiorum (Fraissinet-Tachet and Reymond 1995). Conserved regions in the carboxyl terminal have an important effect on protein expression and in vitro purification (DellaPenna and Bennett 1988; Liang et al. 2015); however, they might not interfere with the PG-inhibiting protein (PGIP) action (Cook et al. 1999). When the residue His234 of Fusarium moniliforme endo-PG mutated to Lys, enzyme activity

Corresponding authors: Fuguang Li, E-mail: aylifug@163.com; Yuxia Hou, E-mail: houyuxia@cau.edu.cn

Compliance with ethical standards: This study did not involve human participants and animals, and the plant of interest is not an endangered species.

Yuxia Hou, Fuguang Li, and Nana Liu conceived and designed the experiments. Nana Liu executed the experiments. Nana Liu, Xiaowen Ma Yun Sun, Xueyan Zhang, and Xiaowen Ma analyzed the data. Nana Liu wrote the manuscript. Yun Sun and Xueyan Zhang contributed the reagents, materials, and analysis tools.

*The $\boldsymbol{e}$-Xtra logo stands for "electronic extra" and indicates that five supplementary figures and two supplementary tables are published online.

Accepted for publication 19 February 2017.

C 2017 The American Phytopathological Society was abolished (His234 $\rightarrow$ Lys), and when Ser237 and Ser240 mutated to Gly, enzyme activity was reduced by $48 \%$ and $6 \%$ of that in nonmutated forms, respectively; however, the variant enzymes were still able to interact and bind to PGIP (Markovič and Janeček 2001).

Endo-PGs have been receiving much attention because of their pathogenicity. Research has shown that PG is one of the important pathogenic factors of banana Fusarium wilt (Bulantseva et al. 2005), and $\mathrm{PG}$ is a pathogenicity factor in the Claviceps purpurea/rye interaction (Oeser et al. 2002). A previous study also demonstrated that Botrytis cinerea endopolygalacturonase2 (BCPG2) is an important virulence factor for this species (Kars et al. 2005). The different forms of PG may be derived from different genes or they can be genetically modified by different glycosylation processes (Zhang et al. 1999). In addition, gene deletion or activation of other genes within the pectinase gene cluster during the process of infection can compensate for the function of PG, so the single gene deletion does not display a significant virulence reduction (Ruiz et al. 2016). The mutant strain resulting from the deletion of Cryphonectria parasitica endo-PG gene had identical virulence to that of the wild strain (Gao et al. 1996), indicating the presence of other PG genes. Deletion of mutant strains in the culture medium with higher PG activity than that of the infected host suggested that the PG gene is not related to virulence (Di Pietro and Roncero 1996; Di Pietro et al. 1998).

Most fungal PGs are extracellular enzymes, whose secretion depends on an inducer (Reymond-Cotton et al. 1996). For example, pectin can induce $S$. sclerotiorum PG gene expression whereas glucose cannot ( $\mathrm{Li}$ et al. 2004). In addition, PG transcription activity rapidly increased in hosts invaded by Colletotrichum lindemuthianum (Dumas et al. 1999), suggesting that PG is involved in the pathogen penetration through the cell wall by degrading pectin. PG expression is also regulated by other factors: PG activity significantly decreased in Monilinia fructicola cultured in a medium containing $\mathrm{Ca}^{2+}$, suggesting that this ion is a negative regulator of fungal $\mathrm{PG}$ expression (Biggs et al. 1997).

Verticillium dahliae Kleb is the pathogen causing cotton Verticillium wilt (Sal'Kova and Guseva 1965). Studies have shown that pectinase activity and Verticillium wilt virulence were positively correlated: highly virulent defoliating Verticillium wilt strains express higher pectinase activity (Puhalla and Howell 1975). Thus, pectinase has been regarded as the important biochemical factor in $V$. dahliae virulence (Bulantseva et al. 2005; Carder et al. 1987).

This study aimed to assess the role of $V$. dahliae PG1 (VDPG1) and F. oxysporum f. sp. vasinfectum PG1 (FOVPG1) in pathogenicity, virulence, and symptom development on cotton, to characterize their 
biochemical properties, and to determine the necrotizing activity of each enzyme in resistant and susceptible cotton cultivars. Although pectinase activity is a vital factor in the virulence of $V$. dahliae and PG is a kind of pectinase, the role of VDPG1 and FOVPG1 in virulence and pathogenicity to cotton have never been reported. We present the evidence that both proteins are essential for a successful necrosis of the host tissue; hence, they are considered as pathogenicity factors.

\section{Materials and Methods}

Plant material and preparation of fungal PG. Cotton seedlings of the resistant cultivar Zhongzhimian 2 (original strain GK44) and the susceptible cultivar Xinluzao 33, inoculated with $V$. dahliae (strain Vd991) and F. oxysporum f. sp. vasinfectum (strain AYF-1) (Zhang et al. 2011), were used in gene expression analysis. Virulent strains of $V$. dahliae $\mathrm{Vd} 991$ and $F$. oxysporum $\mathrm{f}$. sp. vasinfectum were grown in potato dextrose agar ( $200 \mathrm{~g} /$ liter potato, $20 \mathrm{~g} /$ liter dextrose, and $15 \mathrm{~g} /$ liter agar) at $25^{\circ} \mathrm{C}$ for a week. Colonies were then transferred to 500-ml Erlenmeyer flasks containing $100 \mathrm{ml}$ Czapek's liquid medium and grown at $25^{\circ} \mathrm{C}$ and $200 \mathrm{rpm}$ for 7 days. Concentrated spore solutions were then prepared using $10^{7}$-conidia $/ \mathrm{ml}$ suspensions.

VDPG1 and FOVPG1 cloning. Total RNA from $V$. dahliae Vd991 and $F$. oxysporum $\mathrm{f}$. sp. vasinfectum was extracted with Trizol (TIANGEN Biotech Co, LTD., Beijing, China). First-strand cDNA was obtained from total RNA using a reverse transcription kit

$\begin{array}{llll}\text { BCPG1 } & 1 & \text { KTSCATIVLSALSVPSGTTLDLTGLKSGTHVVFEGTTTFGYEEWSGPLFSVSGTDITVTG } \\ \text { VdPG1 } & 1 & \text { KKTCDSITLNNIAVPAGTTLDLSSHKSGAHVVFQGKTTFGYKEWEGPLIQISGEKITVEG } \\ \text { VnPG1 } & 1 & \text { KKSCTTITLSNIAVPAGTTLDLTGLTKGTSVIFSGTTSFGYKEWEGPMISIAGTGIKVSG } \\ \text { FOVPG } & 1 & \text { KAGRSTITLNNIAVPAKTTLDLTKLNDGTHVIFQGKTTFGYAEWEGPLISFTGNNILIEG } \\ \text { FVPG1 } & 1 & \text { KAGCSTIILNNIAVPAKTTLDLTKLNDGTHVIFQGKTTFGYAEWEGPLISFTGNNLLIEG }\end{array}$

BCPG1

61 ASGSKIDGQGAKYWDGKGTNGGKTKPKFFYAHSLKGKSTISGINILNSPVQVFSINGASG

VdPG1 61 ASGHIIDADGARWWDGQGGNGGKTKPKLLAVKGLNN-SIVKGLNFKDOPVHGISVNTVNN

VnPG1 61 ASGHVIDGNGAAWWDGKGSNGGKTKPKFFYAHKMID-STITGLNIKNHPVQCFSVNGANN

FOVPG 61 AAGHSIDCEGKRWWDGKGSNGGKKKPKFFSAHSLKN-SNIKNLNVLNTPVQAFSINSVTN

FVPG1 61 ASGHSIDCEGKRWWDGKGSNGGKTKPKFFSAHSLKN-SNIKNLNVLNTPVQAFSINSVTN

BCPG1 121 ITISNIHIDNSAGDAGK̈LGHNTDAFDVGSSSDITISGANVQNQDDCLAINSGTGI TFTGG VdPG1 120 LQI IDVTLDASAGDS-KGGHNTD GFDVGNAQNILISGAIVKNQDDCLAINSGTNITFTGG VnPG1 120 LVIDSVTTDNSAGD TGKLGHNTDAYDVGSSTNIVISNAVVKNQDDCLAINSGTNI TFTGG FOVPG 120 LGVYGVHMDNSLGDS-LGGHNTDAFDVGSSTGVYISGAVVKNQDDCLAINSGTNI TFTGG FvPG1 120 LGVYGVHMDNSLGDS-LGGHNTDAFDVGSSTGVYISGAVVKNQDDCLAINSGTNI TFTGG

BCPG1 181 TCSGGHGLSIGSVGGRSDNTVSDIIIESSTVKNSANGVRIKTVSGATGSVSGVTYKDITL VdPG1 179 NCSGGHGLSIGSVGNRSNNVVKTIRINNSKISNSDNGVRIKTISGATGSVSDVIYDTITL VnPG1 180 SCSGGHGLSIGSVGGRSDNDVKDVTISSSTITNSDNGVRIKTVSGATGSVSGVTYKDI TL FOVPG 179 NCSGGHGLSIGSVGGRSDNTVKTVRILNSSISNSDNGVRIKTVSGATGSVSDVKYDTITL FvPG1 179 NCSGGHGLSIGSVGGRSDNTVKTVRILNSAISNSDNGVRIKTVSGATGSVSDVKYDTITL $* * * * * * * * * * * * * * *$

BCPG1 241 SGITSYGVVVQQDYKNGSPTGKPTSGVPI TDVTFSNVKGTVSSSATNVYVLCA--KCSGW VdPG1 239 SNIAKNGIVIEQDYENGSPTGTPTAGVPI TGLTINKVVGTVASKGTNVY ILCAKGACSNW VnPG1 240 KNIAKYGIVIEQDYENGSPTGTPTTGVPI TDLTVSGVKGTVASSGTNIYILCGKGSCSDW FOVPG 239 SNIAKYGIVIEQDYENGSPTGTPTAGVPI TDVTINKVTGTVKSSGTDVDILCA--NCKNW FvPG1 239 SNIAKYGIVIEQDYENGSPTGTPTAGVPITDVTINKVTGTVKSSGTDVYILCA--NCKNW

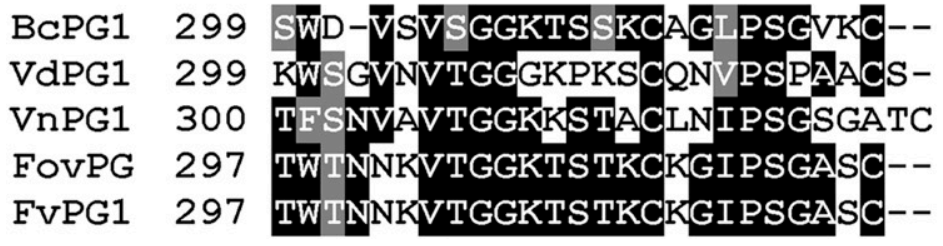

Fig. 1. Multiple alignment of putative amino acid sequences of polygalacturonases (PGs) from Verticillium dahliae (VDPG1), Fusarium oxysporum f. sp. vasinfectum (FOVPG1), Botrytis cinerea (BcPG1, GenBank Accession No. AY665552.1), Colletotrichum fioriniae PJ7 (CofPG, XP_007599497.1), Colletotrichum lindemuthianum (CIPG1, CAA64727.1), Cryphonectria parasitica (CrpPG, AAB36616.1), Fusarium verticillioides 7600 (EWG53332.1), and Venturia nashicola (VnPG1, BAG72132.1). The conserved regions of PGs are indicated by red boxes. 
(Takara, Shiga, Japan). VDPG1 and FOVPG1 were amplified using the VDPG1 and FOVPG1 primers (Supplementary Table S1). The reverse transcription (RT)-PCR conditions were the following: denaturation at $94^{\circ} \mathrm{C}$ for $3 \mathrm{~min}$ followed by 35 cycles at $94^{\circ} \mathrm{C}$ for $30 \mathrm{~s}, 45$ to $55^{\circ} \mathrm{C}$ for $30 \mathrm{~s}$, and $72^{\circ} \mathrm{C}$ for $1 \mathrm{~min}$, and a final extension step at $72^{\circ} \mathrm{C}$ for $7 \mathrm{~min}$. Rapid amplification of the $3^{\prime} \mathrm{cDNA}$ end ( $\left.3^{\prime} \mathrm{RACE}\right)$ PCR was performed with two nested gene-specific sense primers, $3^{\prime}$ VdPGO and 3' VdPGN, and 3' FovPGO and 3' FovPGN, for VDPG1 and FOVPG1, respectively, following the specifications of the $3^{\prime}$ RACE kit (Takara). The 5' RACE first-strand cDNA synthesis was performed with a $5^{\prime}$ RACE kit according to the manufacturer's instructions (Invitrogen, Carlsbad, CA). The tailed cDNA was used as a template for amplification with two nested primers and the adapter primers 5' VdGSP1, 5' VdGSP2, and 5' VdGSP3; and 5' FovGSP1, $5^{\prime}$ FovGSP2, and $5^{\prime}$ FovGSP3 for VDPG1 and FOVPG1, respectively. The RT-PCR started at $94^{\circ} \mathrm{C}$ for $5 \mathrm{~min}$, followed by 33 cycles at $94^{\circ} \mathrm{C}$ for $30 \mathrm{~s}, 45$ to $55^{\circ} \mathrm{C}$ for $30 \mathrm{~s}$, and $72^{\circ} \mathrm{C}$ for $1 \mathrm{~min}$, and a final extension step at $72^{\circ} \mathrm{C}$ for $7 \mathrm{~min}$. The amplified fragments were cloned into pMD18-T and sequenced.

Sequence and phylogenetic analyses. A homology search of the NCBI databases was conducted to verify that the obtained sequences encoded VDPG1 and FOVPG1. Phylogenetic analysis was carried out in MEGA 5.1. and Clustal Omega (http://www.ebi.ac.uk/Tools/msa/ clustalo). BoxShade (http://www.ch.embnet.org/software/BOX_form. html) and SMART (http://smart.embl-heidelberg.de) were used for multiple protein sequence alignment and domain structure prediction, respectively.

RNA isolation and qRT-PCR. Total RNA was isolated using an RNA Extraction Kit (Biomed Co. Ltd., Bangkok, Thailand) from the resistant Zhongzhimian 2 and susceptible Xinluzao 33 cotton cultivar seedlings inoculated with $V$. dahliae $\mathrm{Vd} 991$ and $F$. oxysporum $\mathrm{f}$. sp. vasinfectum (Dowd et al. 2004; Gao et al. 2011). First-strand cDNA was synthesized using a cDNA Reverse Kit (Takara). VDPG1 and FOVPG1 expression was assessed using the primers qVDPG and qFOVPG. The endogenous genes $V D U B Q$ and $F O V U B Q$ were used as internal controls and amplified with the primers VDUBQ and FOVUBQ. Reactions were prepared in a total volume of $20 \mu \mathrm{l}$ with SYBR Premix Ex Taq (Tli RNaseH Plus) (Takara). Amplification was performed on an ABI 7500 thermocycler (Applied Biosystems, Foster City, CA) and gene expression was determined by the $2^{-\Delta \Delta C T}$ method. Data were analyzed in Origin8 (OriginLab, Northampton, MA) as described by Wang et al. (2011).

In-planta $V$. dahliae and $F$. oxysporum f. sp. vasinfectum biomass quantification. Quantification of V.dahliae and F. oxysporum f. sp. vasinfectum biomass was performed (Ellendorff et al. 2009; Zambounis et al. 2007). Briefly, cotton seedlings inoculated with $V$. dahliae and $F$. oxysporum f. sp. vasinfectum per time point were harvested and pooled. Then DNA was extracted from $100 \mathrm{mg}$ of the samples, and biomass was determined by real-time PCR using SYBR Premix Ex Taq (Tli RNaseH Plus) (Takara). To assess the biomass of $V$. dahliae, the fungus specific ITS1-F primer and the $V$. dahliae-specific reverse primer ST-Ve1-R (Fradin et al. 2011) were used. And the $F O V$-specific primers (Zambounis et al. 2007) were used to measure the biomass of $F$. oxysporum f. sp. vasinfectum. For sample calibration, the cotton Ubiquitin was used. Real-time PCR conditions are the same as those described above.

VDPG1 and FOVPG1 expression in different substrates. F. oxysporum f. sp. vasinfectum and V. dahliae Vd991 were inoculated

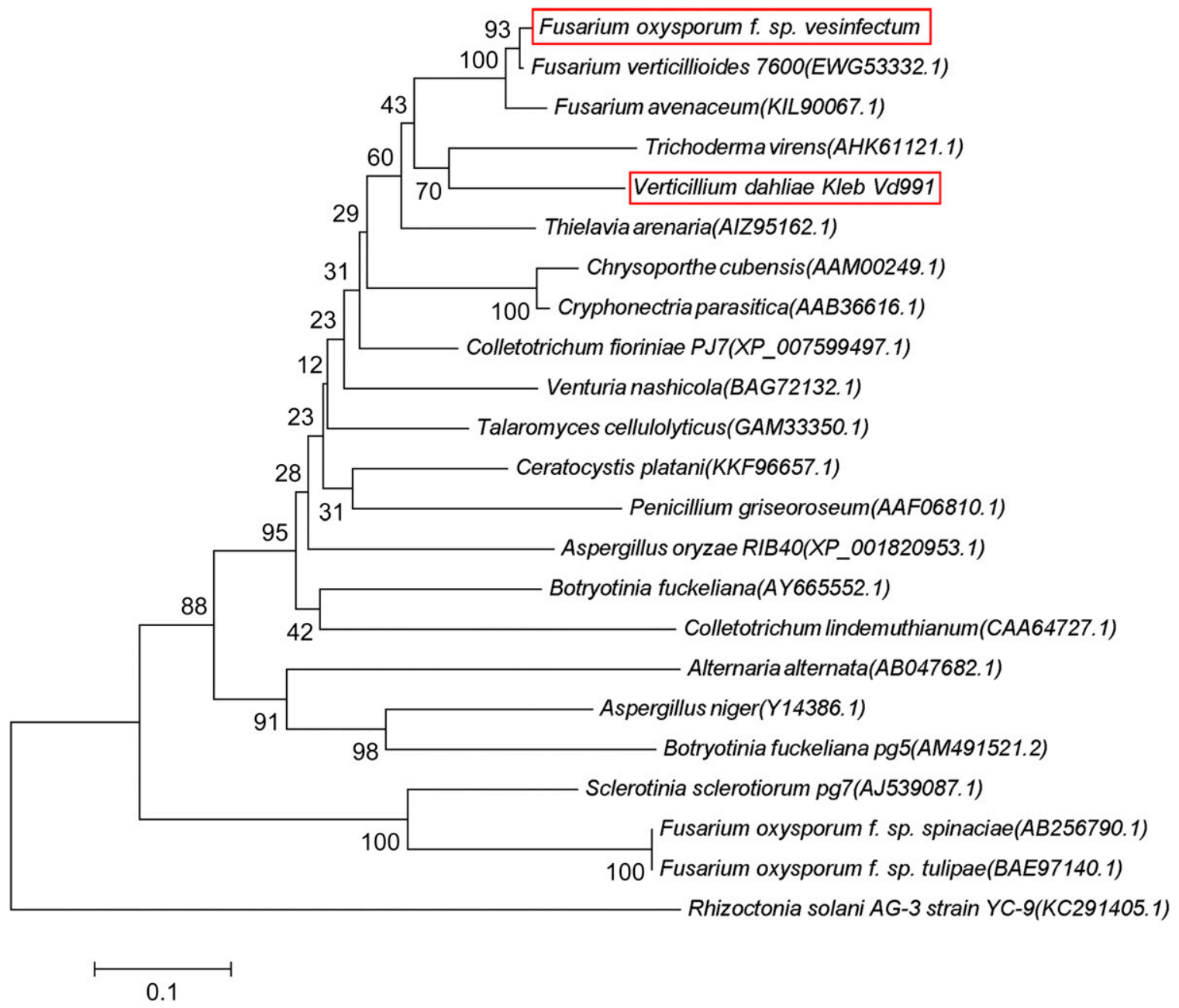

Fig. 2. Phylogenetic relationships between several fungal polygalacturonases (PGs). The neighbor-joining tree was inferred from the genetic distance between aligned protein sequences using MEGA 5.1. VDPG1 and FOVPG1 sequences obtained in this study are indicated by red boxes. Asterisks indicate the active sites of PGs. 
in a Marcus induction culture medium $\left(\mathrm{KNO}_{3} 2.0 \mathrm{~g}, \mathrm{KCl} 0.5 \mathrm{~g}\right.$, $\mathrm{FeSO}_{4} 0.01 \mathrm{~g}, \mathrm{~K}_{2} \mathrm{HPO}_{4} 1.0 \mathrm{~g}, \mathrm{MgSO}_{4} \cdot 7 \mathrm{H}_{2} \mathrm{O}$, Vitamin B1 $0.1 \mathrm{mg}$, L-asparagine $0.5 \mathrm{~g}$, citrus pectin $10 \mathrm{~g}$, sterile water volume to 1 liter, $\mathrm{pH} 5.0$ [James and Dubery 2001]) and grown for 7 days at $28^{\circ} \mathrm{C}$; $V$. dahliae and $F$. oxysporum f. sp. vasinfectum were then grown on plates containing potato extract, pectin (the inducer) and agar, and those grown on plates containing potato extract, glucose, and agar were used as control (Dumas et al. 1999), the other conditions were unchanged. To determine the expression of VDPG1 and FOVPG1 in the different media, fungal RNA was extracted, and first-strand cDNA was synthesized using a cDNA Reverse Kit (Takara) and the specific VDPG1 and FOVPG1 primers, as well as the primers VDUBQ and FOVUBQ for the $V D U B Q$ and $F O V U B Q$ reference genes.

Expression and purification of VDPG1 and FOVPG1. VDPG1 and FOVPG1 were amplified using VdPG32a and FovPG32a as primers, respectively, and cloned into a PET-32a expression vector (Supplementary Figs. S3 and S4). The construct was transformed into Escherichia coli BL21DE3 following the protocol of CWBIO competent cell BL21 DE3 (CW BIO, Beijing, China). A DNA sample $(<10 \mathrm{ng})$ was added to the competent cell BL21 DE3, which was previously thawed on ice, and placed on ice for $30 \mathrm{~min}$, followed by a heat pulse for $45 \mathrm{~s}$ at $42^{\circ} \mathrm{C}$ and chilling for $2 \mathrm{~min}$ on ice. SOC medium (500 $\mu \mathrm{l} ; 2 \%$ Bacto Tryptone, $0.5 \%$ Bacto Yeast Extract, $10 \mathrm{mM}$ $\mathrm{NaCl}, 2.5 \mathrm{mM} \mathrm{KCl}, 10 \mathrm{mM} \mathrm{MgSO}_{4}, 10 \mathrm{mM} \mathrm{MgCl}_{2}, 20 \mathrm{mM}$ glucose) was added to the cells and the reaction was incubated at $37{ }^{\circ} \mathrm{C}$ with shaking for $1 \mathrm{~h}$. An adequate amount of transformed cells was smeared on plates of L-broth plus ampicillin and incubated at $37^{\circ} \mathrm{C}$ overnight. Monoclones were cultured at $37^{\circ} \mathrm{C}$ in Luria-Bertani broth supplemented with $100 \mu \mathrm{g} / \mathrm{ml}$ ampicillin induced with $1.0 \mathrm{mM}$ IPTG until the optical density reached 0.6 to 0.8 . The monoclones were then cultured for another $6 \mathrm{~h}$ at $28^{\circ} \mathrm{C}$ with oscillation. Cells were harvested after centrifugation for $20 \mathrm{~min}$ at $10,000 \times g$. The expression of soluble VDPG1 was verified by sodium dodecyl sulfate polyacrylamide gel electrophoresis (SDS-PAGE) (Maceira et al. 1997; Di Pietro and Roncero 1996; Zhang et al. 1999) and purified using a 6x His-Tagged Protein Purification Kit (CW BIO). FOVPG1 was the inclusion body protein expressed in precipitation; therefore, its purification followed the denaturation and refolding method and conditions reported by Afzal and Lightfoot (2007), Borin et al. (1996), Cooke et al. (1976), and Yang et al. (2009). The 6x His fusion tags and the trigger factors encoded in the vector were removed using a Thrombin Cleavage Capture Kit (Novagen, Madison, WI).

Endo-PG activity measurements. PG activity was measured in agarose plate diffusion experiments using $0.8 \%$ agarose and $0.5 \%$ PGA (Sigma-Aldrich, St. Louis, MO) in $0.1 \mathrm{M}$ sodium acetateacetic acid buffer ( $\mathrm{pH}$ 4.8) (Taylor and Secor 1988). VDPG1 and FOVPG1 were spotted on plates and incubated at $30^{\circ} \mathrm{C}$ for $12 \mathrm{~h}$. Thereafter, the gel was stained with $0.05 \% \mathrm{w} / \mathrm{v}$ ruthenium red in
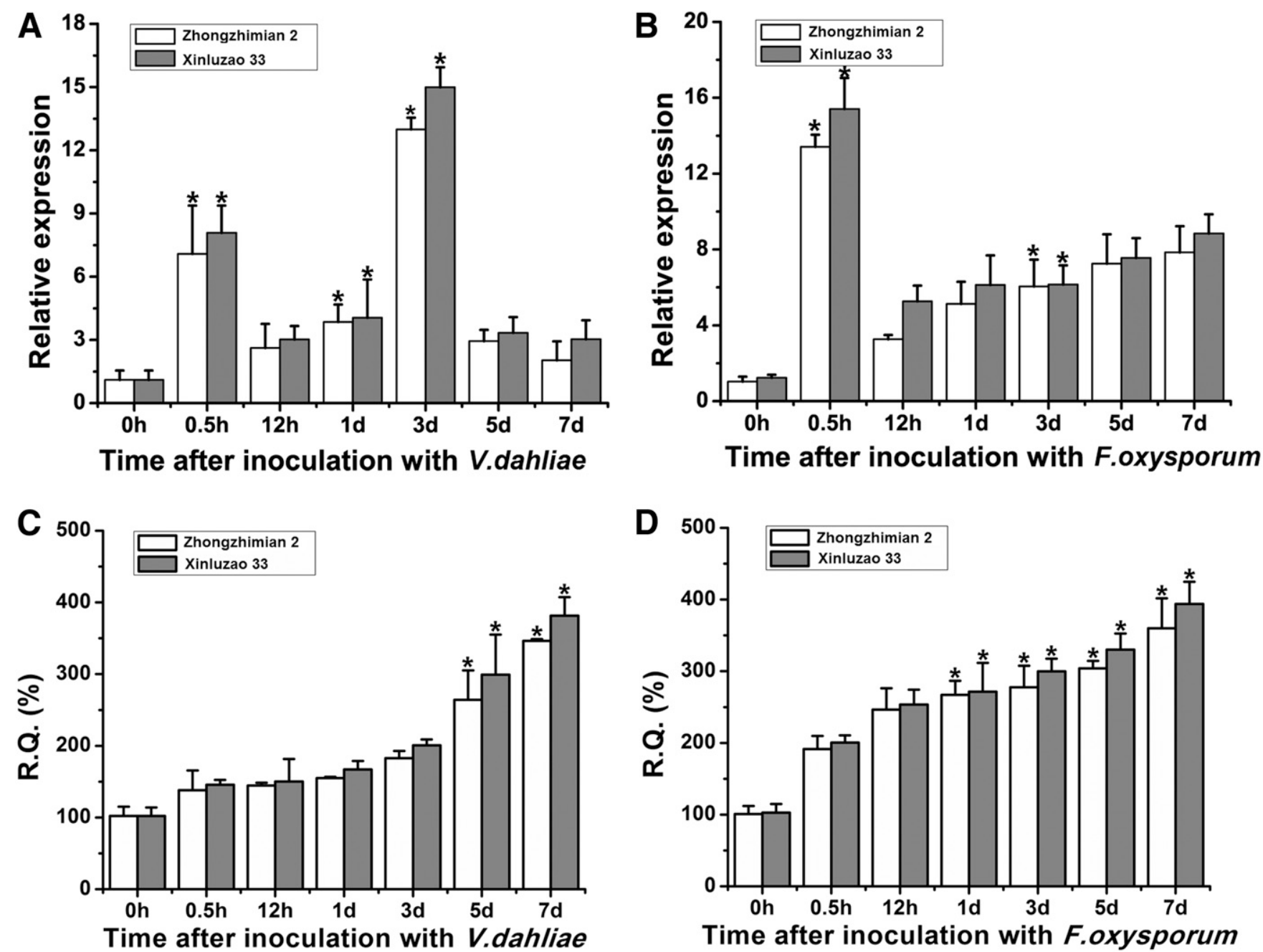

Fig. 3. Expression of VDPG1 and FOVPG1 obtained in real-time polymerase chain reaction (qRT-PCR). A, VDPG1 expression in Zhongzhimian 2 and Xinluzao 33 at $0,0.5$, and $12 \mathrm{~h}$, and at $1,3,5$, and 7 days after inoculation with Verticillium dahliae Vd991. B, FOVPG1 expression in both cultivars at $0,0.5$, and $12 \mathrm{~h}$, and at $1,3,5$, and 7 days after inoculation with Fusarium oxysporum f. sp. vasinfectum. Expression was compared with that in control plants treated with Czapek's liquid medium. C, Quantification of $V$. dahliae biomass in susceptible and resistant cultivars. Fungal biomass was determined by quantitative real-time PCR (R.Q.) in $0,0.5,12 \mathrm{~h}$, and at $1,3,5$, and 7 days after inoculation with V. dahliae Vd991. D, Quantification of $F$. oxysporum f. sp. vasinfectum biomass in susceptible and resistant cultivars. Fungal biomass was determined by quantitative real-time PCR (R.Q.) in $0,0.5,12 \mathrm{~h}$, and at $1,3,5$, and 7 days after inoculation with F. oxysporum f. sp. vasinfectum. $0 \mathrm{~h}$ is set to $100 \%$. Data were collected from three independent biological replicates and presented as means \pm standard errors $(n=3)$. Asterisks indicate a significant difference compared with control (least significance differences [LSD], $P<0.05)$. 
water and thoroughly rinsed with sterile water (Taylor and Secor 1988). Enzymatic activity was measured in reducing units. A reducing unit is the amount of enzyme required to release reducing groups at $1 \mathrm{M} / \mathrm{min}$ using D-galacturonic acid as the standard (Wang et al. 2013). To determine steady-state parameters, initial reaction rates were measured with increasing the PGA concentrations. $V_{\max }$ and $K_{\mathrm{m}}$ values were calculated from production rates by nonlinear regression analysis using the Michaelis-Menten equation. Phosphate-citrate (McIlvain) buffers with $\mathrm{pH} 2$ to 11 were used to determine the optimal reaction $\mathrm{pH}$ (Kars et al. 2005).

The necrotizing activity analysis of recombinant proteins in cotton. Infiltration was conducted with a needleless $1-\mathrm{ml}$ or 2-ml syringe placed against the leaves of resistant Zhongzhimian 2 and susceptible Xinluzao 33 cotton cultivars (Kars et al. 2005). Control cotton cultivars were inoculated with mixed buffers that contained bacterial lysis buffer, binding buffer, and elution buffer (Wang et al. 2013). In every experiment, each sample was infiltrated in one section per leaf, two leaves per plant, and the assays were performed with at least three plants. Experiments were performed at least thrice with batches of enzymes. The average lesion size and the corresponding standard deviations were calculated for each treatment. Data were analyzed statistically using SPSS (IBM Corp., Armonk, NY). And data analysis was performed by one-way analysis of variance (ANOVA). For comparison of two groups, Student's $t$-test was used.

To measure the lesion area induced by the protein, infiltrated leaves were stained with trypan blue (Liu et al. 2016; Zhu et al. 2014). A stock solution of trypan blue was prepared with $10 \mathrm{ml}$ $85 \%$ lactic acid, $10 \mathrm{ml}$ phenol, $10 \mathrm{ml}$ distilled water, and $10 \mathrm{mg}$ trypan blue (Sigma-Aldrich). A working solution was then prepared by diluting the stock solution in $95 \%$ ethanol in the ratio 1:1. Infected leaves were incubated in the working solution, boiled for $1 \mathrm{~min}$, cooled, and left at room temperature overnight. Chlorophyll was removed with chloral hydrate $(1.25 \mathrm{mg} / \mathrm{ml}$ ) (Zhu et al. 2014), and leaves were examined and photographed under a $4 \times / 0.25 \mathrm{nu}-$ merical aperture objective in an Eclipse Ti microscope (Nikon, Japan).

Cell wall preparation and determination of hydroxyproline content. The cell wall was extracted from the two cultivars and inoculated with VDPG1, FOVPG1, and buffer; the buffer was used as a control. Cell wall preparation followed the protocol described by Hammerschmidt et al. (1984). The upper $2 \mathrm{~cm}$ of hypocotyl tissue (minus the cotyledons) were excised, weighed, frozen in liquid nitrogen, and powdered. This powder was then suspended in $15 \mathrm{mM}$ potassium phosphate buffer ( $\mathrm{pH} 7.2,10 \mathrm{ml} /$ gram fresh weight), briefly centrifuged, and the resulting pellet was resuspended in 10 volumes of $15 \mathrm{mM}$ potassium phosphate buffer. The pellet was then washed by resuspension and centrifugation in $0.5 \mathrm{M} \mathrm{NaCl}$ (two times), $1.0 \mathrm{M} \mathrm{NaCl}$ (two times), and distilled water (four times). The final pellet consisting of cell walls only was freeze-dried and stored with a desiccant at $-20^{\circ} \mathrm{C}$ until analyzed.

Hydroxyproline oxidation in sodium hypobromite forms pyrrole compounds, which, in acidic conditions at $70^{\circ} \mathrm{C}$, react with p-dimethylaminobenzaldehyde generating a rose-red chromophore (Kivirikko and Liesmaa 2009). Hydroxyproline absorption values in the range of 1 to 20 were determined at $560 \mathrm{~nm}$.

Host-defense gene expression after VDPG1 and FOVPG1 infiltration. Cotyledons from 3-week-old plants were infiltrated with VDPG1 and FOVPG1. Because the hydroxyproline content increases until day 3 postinfiltration in both PGs, the RNA of Zhongzhimian 2 and Xinluzao 33 whole plant was extracted 3 days after the infiltration and first-strand DNA was obtained by reverse transcription. To detect the expression of the host-response genes $G h P A L$, GhPOD, GhNPRl, GhNDRl, and GhVe1, RT-PCR amplification was performed using cDNA as template and the specific primers listed in Supplementary Table $\mathrm{S} 1$. The endogenous gene GhUBQ was used as an internal control and cotton plants that were infiltrated with buffer solution that dissolved the proteins were used as negative controls.

\section{Results}

Cloning and characterization. Using RT-PCR and RACE, we cloned the full-length cDNA sequences of VDPG1 and FOVPG1 (GenBank Accession Nos. KT306968 and KT306967, respectively) (Supplementary Table S2). The VDPG1 gene contained an 1110-bp open reading frame (ORF) encoding a protein of 370 amino acids, whereas FOVPG1 contained a 1080-bp ORF and encoded a protein of 360 amino acids. VDPG1 had a putative N-terminal signal peptide with 18 amino acids, seven putative $\mathrm{N}$-glycosylation sites, and six parallel beta-helix repeats, whereas FOVPG1 had N-terminal signal peptide of 17 amino acids, four putative $\mathrm{N}$-glycosylation sites, and four parallel beta-helix repeats (Supplementary Figs. S1 and S2). Both proteins contained the consensus sequence characteristic of PGs (Fig. 1), such as GHNTD, NQDDC, and RIK, and RNSCTGGHGISIGS, which is considered the active site of endo-PGs (Centis et al. 1997).

Using the basic local alignment search tool against a protein database (BLASTP), VDPG1 and FOVPG1 amino acid sequences were subjected to a multiple sequence homology comparison. Results revealed a high homology between VDPG1 and Thielavia
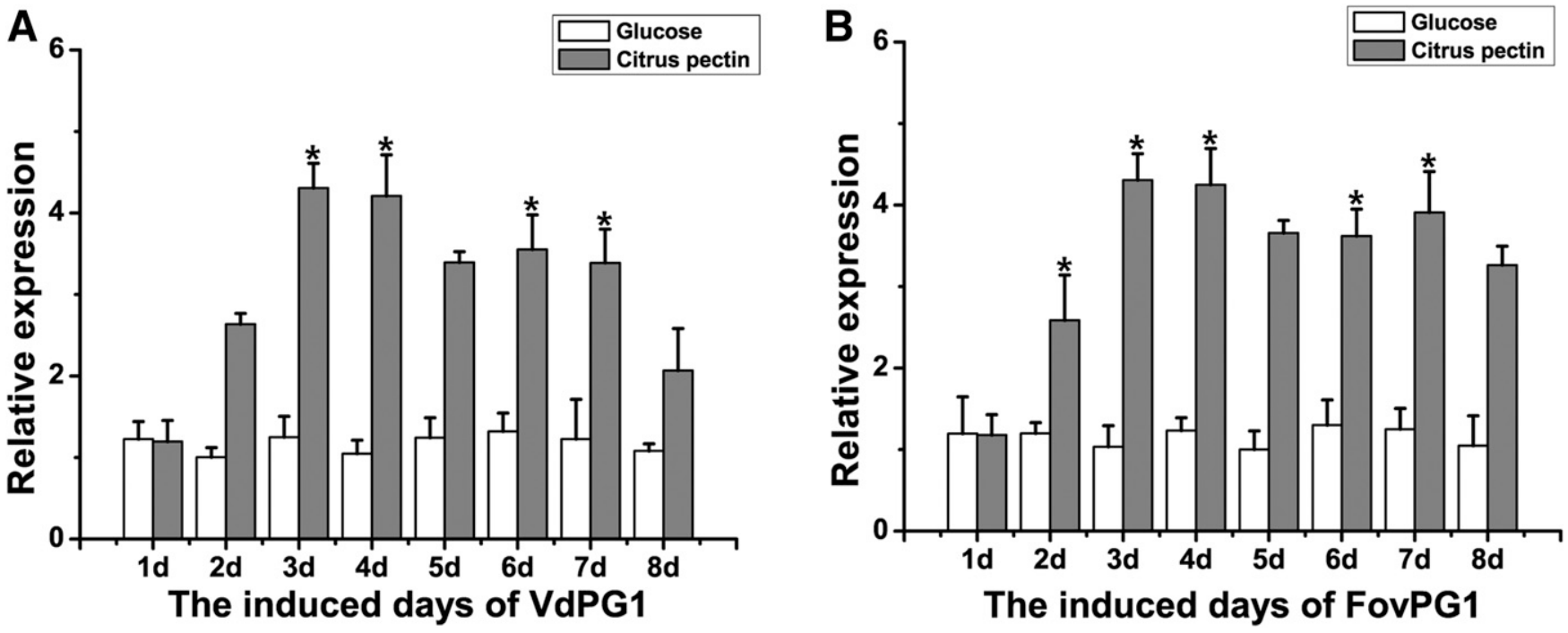

Fig. 4. VDPG1 and FOVPG1 expression in different substrates. A, VDPG1 expression in Verticillium dahliae Vd991 inoculated in glucose and citrus pectin mediums from 1 to 8 days. B, FOVPG1 expression in Fusarium oxysporum f. sp. vasinfectum inoculated in glucose and citrus pectin mediums from 1 to 8 days. Data were collected from three independent biological replicates and presented as means \pm standard errors $(n=3)$. Asterisks indicate a significant difference at $P<0.05$ when compared with control data based on the results of Student's $t$-test. 
arenaria PG, with FOVPG1 and FvPG1 being in the same branch (Fig. 2).

VDPG1 and FOVPG1 transcripts accumulation and increase of fungal biomass in infected cotton cultivars. VDPG1 and FOVPG1 expression was measured in resistant and susceptible cotton cultivars in response to $V$. dahliae and $F$. oxysporum f. sp. vasinfectum infection, respectively. At $0.5 \mathrm{~h}$ postinfection with $V$. dahliae, in the infected resistant cultivar the transcript level of VDPG1 showed a 7.1-fold increase whereas in the infected susceptible cultivar showed an 8.2-fold increase (Fig. 3A). VDPG1 expression peaked at day 3 postinfection in both cultivars (12.9-fold increase in the infected resistant cultivar and 14.7-fold increase in the infected susceptible cultivar), diminishing to a 2.2-fold increase in the infected resistant cultivar and 3.0-fold increase in the infected susceptible cultivar at day 7 postinfection; both cultivars were not statistically significant in the infection of $V$. dahliae. Fusarium oxysporum $\mathrm{f}$. $\mathrm{sp}$. vasinfectum infection elicited a different response: at $0.5 \mathrm{~h}$ postinfection, there was a 13.0-fold increase in FOVPG1 expression in the inoculated resistant cultivar and a 15.4-fold increase in the inoculated susceptible cultivar; from $12 \mathrm{~h}$ to 5 days postinfection, there was a slight increase in FOVPG1 expression, which was stabilized by day 7 postinfection, there were no significant difference between the two cultivars (Fig. 3B). The colonization of $V$. dahliae and F. oxysporum f. sp. vasinfectum were determined in infected resistant and susceptible

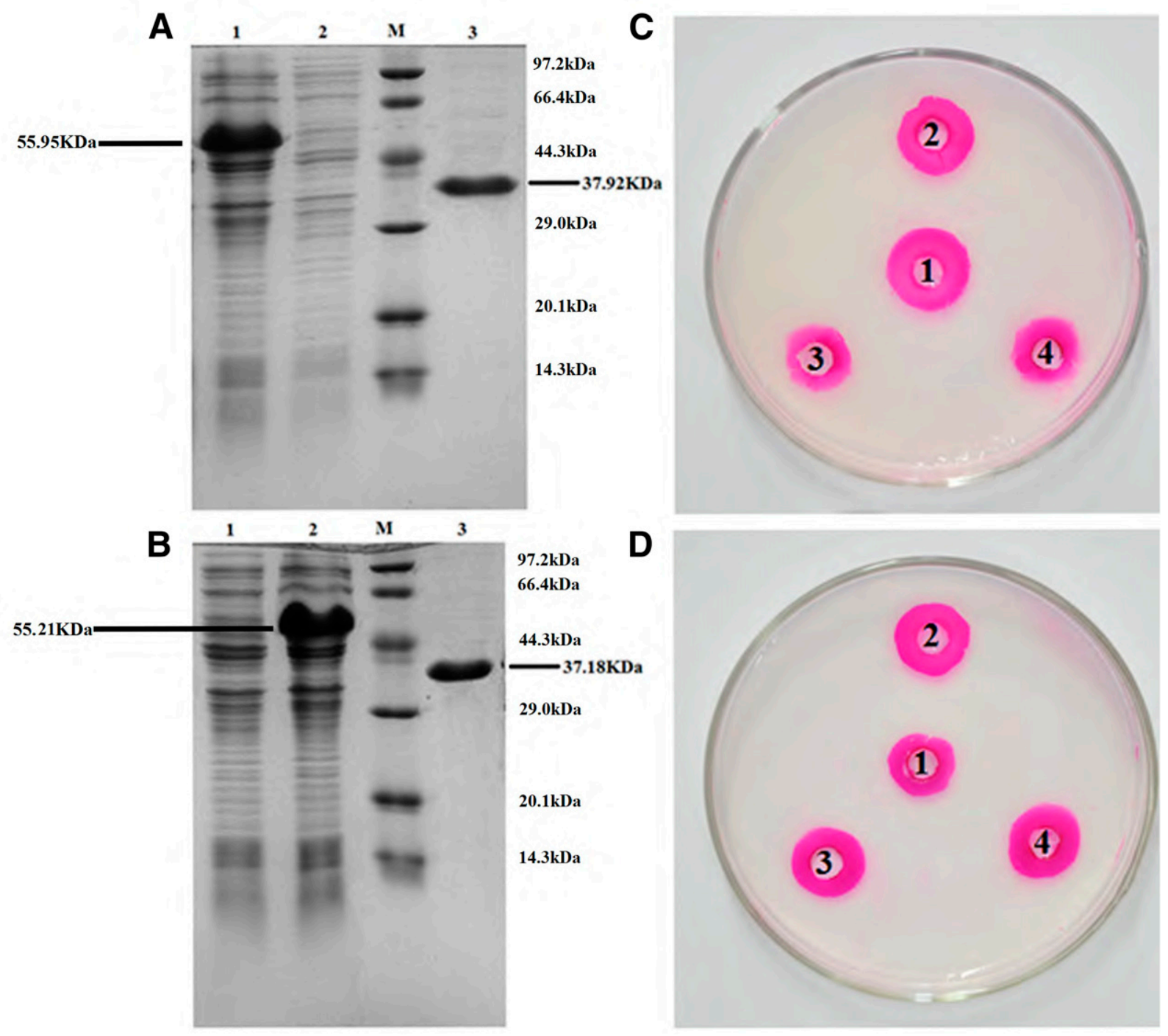

Fig. 5. Purification and characterization of recombinant VDPG1 and FOVPG1. A, VDPG1: Lane 1, total protein (PG + tagged protein) expressed in the supernatant; Lane 2, total protein (PG + tagged protein) expressed in the precipitate; M, Marker; Lane 3, purified VDPG1. B, FOVPG1: Lane 1, total protein (PG + tagged protein) expressed in the precipitate; Lane 2, total protein (PG + tagged protein) expressed in the supernatant; M, Marker; Lane 3, purified FOVPG1. C, activity of purified VDPG1 and D, activity of purified FOVPG1: 1, pure protein obtained from first elution; 2 , pure protein obtained from second elution; 3 , pure protein obtained from third elution; 4, pure protein obtained from fourth elution.

Table 1. Purification and biochemical characterization of endopolygalacturonases from Verticillium dahliae and Fusarium oxysporum f. sp. vasinfectum produced in Escherichia coli. Polygalacturonic acid was used as substrate to determine the steady-state kinetic parameters. Experiments were repeated two times and there were three replicates per sample.

\begin{tabular}{lccccccc}
\hline Enzyme & Molecular weight (kDa) & $\mathbf{p I}^{\mathbf{a}}$ & Optimal $\mathbf{~ p H}$ & $\boldsymbol{V}_{\mathbf{m a x}} \mathbf{b}(\mathbf{U} / \mathbf{m g})$ & $\mathbf{K m}^{\mathbf{c}}(\mathbf{m g} / \mathbf{m l})$ & Production $(\mathbf{m g} /$ liter) & Pure enzyme yield $(\mathbf{m g})$ \\
\hline VDPG1 & 37.92 & 8.68 & 4.8 & 20 & 0.104 & 580 & 100 \\
FOVPG1 & 37.18 & 8.69 & 9 & 16 & 0.131 & 432 & 64 \\
\hline
\end{tabular}

${ }^{\mathrm{a}}$ Isoelectric point.

${ }^{\mathrm{b}} V_{\max }=$ maximum velocity in $\mathrm{U} / \mathrm{mg}$ protein.

${ }^{\mathrm{c}} K_{m}$, $=$ Michaelis-Menten constant in $\mathrm{mg} / \mathrm{ml}$ substrate. 
cotton cultivars. When compared with $0 \mathrm{~h}$, both fungal biomasses increased in the two cultivars after inoculation, and both cultivars were not statistically significant (Fig. 3C and D). In addition, by prolonging of the incubation time, the accumulation of fungal biomass and the growth rate of fungi were slightly higher in the susceptible cultivars than in the resistant cultivars.

VDPG1 and FOVPG1 expression in different substrates. In the culture medium containing $1 \%$ citrus pectin, PG activity increased, gradually reaching a peak at the growing experiment. In the medium containing $1 \%$ galacturonic acid, PG activity was lower than in the medium containing citrus pectin, whereas in the medium containing glucose as the carbon source, there was no obvious PG activity ( $\mathrm{Li}$ et al. 2004). VDPG1 and FOVPG1 substrate specificity was analyzed using glucose and citrus pectin as inducers. In the pectin medium, both VDPG1 and FOVPG1 were expressed from the first to the eighth day of the experiment; the highest expression of VDPG1 showed a 4.3-fold increase 3 days after inoculation, at which expression remained stable until day 7 (Fig. 4A). And FOVPG1 expression also climbed to 4.3 fold over the basal level 3 days after inoculation, then gradually decreased until 7 days (Fig. 4B). In the glucose medium, neither VDPG1 nor FOVPG1 were induced.

Prokaryotic expression and purification of VDPG1 and FOVPG1. Different expression vectors, inducer concentration, inducement temperature (Supplementary Fig. S5), and experiment duration were used to determine the optimal conditions for the prokaryotic expression of VDPG1 and FOVPG1. Results showed that a highly active fusion protein VDPG1 with $37.92 \mathrm{kDa}$ could be obtained using $1 \mathrm{mM}$ PET-32a vector, $28^{\circ} \mathrm{C}$ with $200 \mathrm{rpm}$, and $4 \mathrm{~h}$ (Fig. 5A). Under the same conditions, an active pure $37.18 \mathrm{kDa}$ FOVPG1 could be obtained by precipitation, after denaturation and renaturation (Fig. 5B).

Purified VDPG1 and FOVPG1 activity assays. Agarose plate diffusion was used to determine the activity of purified VDPG1 and
FOVPG1 (Taylor and Secor 1988) and the results showed that all eluents contained highly active PGs (Fig. 5C and D). Using PGA in the medium revealed that the optimal enzyme activity was different for VDPG1 at $\mathrm{pH} 4.8$ and for FOVPG1 at $\mathrm{pH} 9.0$ (Table 1). At $30^{\circ} \mathrm{C}$, PGA hydrolysis indicated that $V_{\max }$ values ranged from 16 to $20 \mathrm{U} / \mathrm{mg}$ and $K_{\mathrm{m}}$ values ranged from 0.104 to $0.131 \mathrm{mg} / \mathrm{ml}$, albeit the overall yield of pure protein was low for the different PGs.

The roles of the two PGs in symptom development and the determination of hydroxyproline content. VDPG1 and FOVPG1 pure solutions were used as prepared. Infiltrations were carried out with $10-\mathrm{ng} / \mu \mathrm{l}$ protein concentrations and $10-\mathrm{U} / \mathrm{ml}$ enzyme activity (Kars et al. 2005). Leaf chlorosis was monitored over several days. Wilting symptoms in Zhongzhimian 2 and Xinluzao 33 were obvious 3 days after infiltrated with VDPG1 and FOVPG1 (Fig. 6B, C, E, and F); the controls infiltrated with bacterial lysis buffer, binding buffer, and elution buffer mixtures showed no symptoms (Fig. 6A and D). In addition, the resistant cultivar Zhongzhimian 2 phenotypically showed no significant differences with the susceptible cultivar Xinluzao 33 after both VDPG1 and FOVPG1 infiltrations (Fig. 6B and E, C and F). Further, Xinluzao 33 cotyledons became yellow and one of them fell off after infiltrated with VDPG1, but after infiltrated with FOVPG1, this cultivar showed only signs of wilting (Fig. 6E and F). Zhongzhimian 2 cotyledons became more wilted after infiltration with FOVPG1 than VDPG1 (Fig. 6B and C).

Hydroxyproline content in the cell wall was determined to further study the biochemical mechanisms occurring in cotton infiltrated with VDPG1 and FOVPG1. Hydroxyproline content and the growth rate were higher in the resistant cultivars than in the susceptible cotton varieties, and both were higher than that of infiltration mixed buffer $(\mathrm{CK})$ (Fig. 6G and $\mathrm{H}$ ), indicating that pathogen infection promoted hydroxyproline accumulation in cotton seedlings; hydroxyproline accumulation was higher and increased earlier in resistant varieties than in susceptible varieties.
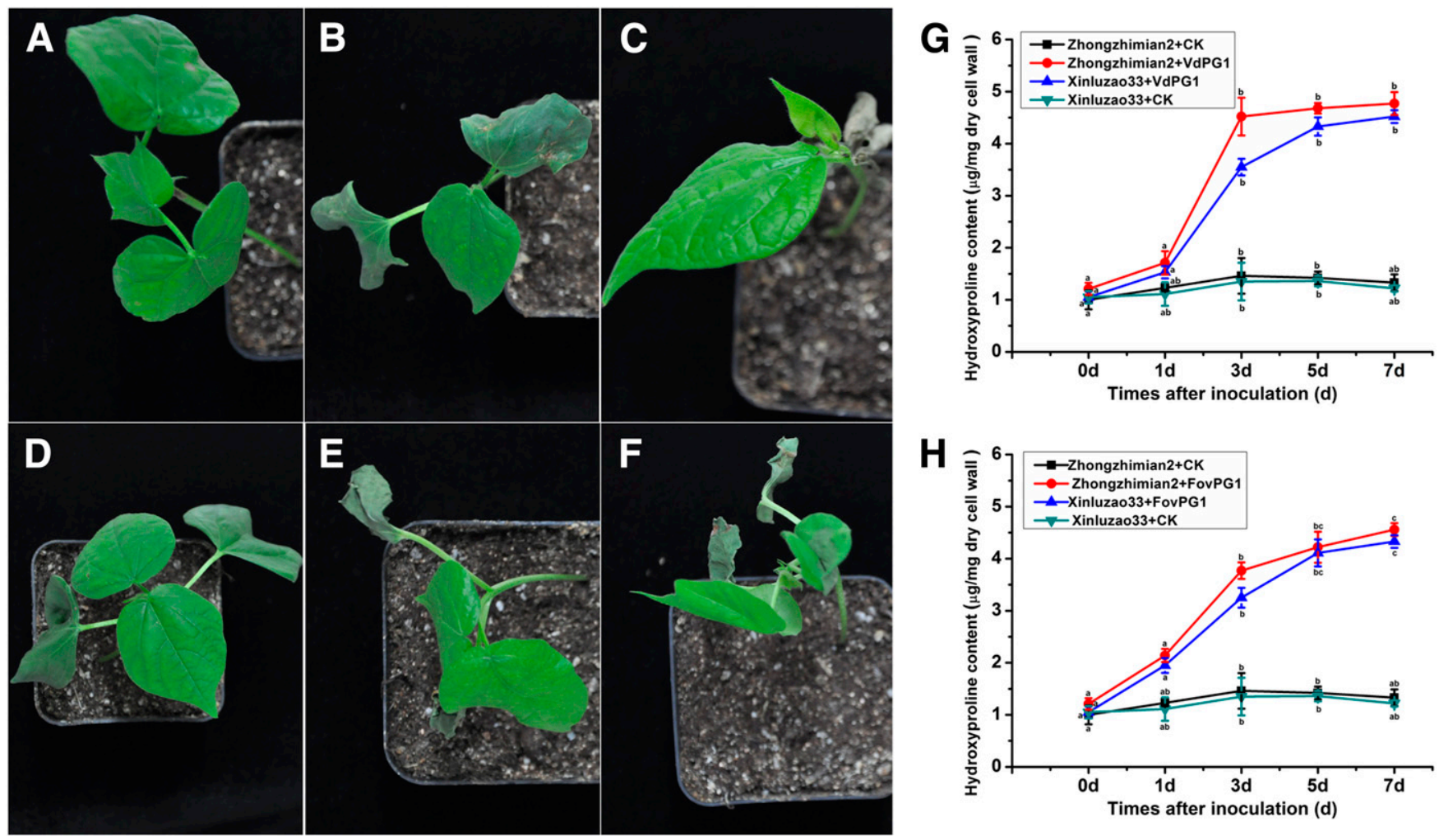

Fig. 6. Pathogenicity of purified VDPG1 and FOVPG1 and determination of hydroxyproline content. A, Zhongzhimian 2 control inoculated with mixed buffers that contains bacterial lysis buffer, binding buffer, and elution buffer. B, VDPG1 inoculation of Zhongzhimian 2. C, FOVPG1 inoculation of Zhongzhimian 2. D, Xinluzao 33 control inoculated with bacterial lysis buffer, binding buffer, and elution buffer. E, VDPG1 inoculation of Xinluzao 33. F, FOVPG1 inoculation of Xinluzao 33. G, cell wall hydroxyproline content in Zhongzhimian 2 and Xinluzao 33 after inoculation with VDPG1 and control check (CK). H, cell wall hydroxyproline content in Zhongzhimian 2 and Xinluzao 33 after inoculation with FOVPG1 and control check (CK). The data points were means of a single experiment carried out in triplicates. Results were shown as means \pm standard errors. Means designated with the same letter were not significantly different according to Tukey's HSD test at $P<0.05$. 
Active VDPG1 and FOVPG1 cause cotton leaf necrosis. Leaf segments of Zhongzhimian 2 and Xinluzao 33 were infiltrated with VDPG1 and FOVPG1 pure solutions. Necrosis, defined as dying tissue, is evidenced by leaves becoming brown and brittle within a few days (Kars et al. 2005). During the 3-day monitoring period, we could discriminate two zones of infiltration: a central necrotic area around the inoculation site and a ring of brown tissue (Fig. 7B, C, H, and I). The zone diameters indicated that VDPG1 and FOVPG1 as pathogenicity factors exhibited larger infiltration-site diameters; leaves infiltrated with bacterial lysis buffer, binding buffer, and elution buffer mixtures (controls) had symptoms that were caused by mechanical damage due to pinholes (Fig. 7A and G).

Lesion area was monitored daily and the area of expanding lesions was measured 3 days postinfiltration. The Zhongzhimian 2 strains formed smaller lesion areas (17.14\%) than Xinluzao 33 strains (26.47\%) after infiltration with VDPG1, and both had larger areas than the control check (CK) (Fig. 7M). For both cultivars the percentage of lesions that expanded beyond the infiltration site was similar after infiltration with FOVPG1: $17.14 \%$ and $18.18 \%$ for Zhongzhimian 2 and Xinluzao 33 strains, respectively (Fig. 7N).

Furthermore, staining of infiltrated leaves with trypan blue revealed smaller lesion areas in the controls than in the leaves infiltrated with VDPG1 (Fig. 7D, E, J, and K) and FOVPG1 (Fig. 7D, F, J, and L). After infiltration with VDPG1 and FOVPG1, PGs diffused along the veins of the two cotton cultivars (Fig. 7E, F, K, and L), whereas buffer mixtures did not cause spreading of the lesions in cotton (Fig. 7D and J). These results suggest a significant role for VDPG1 and FOVPG1 in cotton infiltration, especially during lesion expansion.

Host-defense enzymes and gene expression. Host-defense enzyme activity changes after pathogen infection, causing a series of defensive reactions (Moerschbacher et al. 1988). Therefore, the expression of several genes encoding defense proteins was assessed in Zhongzhimian 2 and Xinluzao 33 varieties after inoculation with the two pathogens to link disease responses with changes in gene expression, and the mixed buffers were used as control checks (CK). RT-PCR data confirmed that the host-defense enzymes peroxidase (POD) and phenylalanine ammonia lyase (PAL) were upregulated after inoculation with VDPG1 and FOVPG1; the results showed similar POD expression levels between the two PGs. However, the expression of PAL was higher after inoculation with FOVPG1 than after inoculation with VDPG1 (Fig. 8A and B). Non-race-specific disease resistance 1 (NDRl) expression was significantly upregulated in Zhongzhimian 2 and Xinluzao 33, although the expression levels were not significantly different between the two cultivars (Fig. 8C). Accordingly, $\mathrm{Vel}$ (encodes receptor-like proteins with an extracellular leucine-rich repeat domain) expression was upregulated in response to VDPG1 and FOVPG1 (Fig. 8D). In addition, Vel expression was higher in response to VDPG1 than in response to FOVPG1 (Fig. 8C and D).

\section{Discussion}

Fungal PGs are members of the family 28 (Markovič and Janeček 2001). Sequence comparisons performed between 43 PGs deriving from Aspergillus, Penicillium, Botrytis, Fusarium, and Sclerotinia, revealed a sequence consistency of $8.9 \%$ and a sequence similarity of $17.4 \%$ (Markovič and Janeček 2001). Multiple alignments of VDPG1 and FOVPG1 indicated that both PGs have the highly conserved sequences GHNTD, NQDDC, and RIK as well as the active site GNCSGGHGLSIGS (Markovič and Janeček 2001) (Fig. 1). The position of some cysteine residues in fungal PGs is very conservative, and there are two sulfur bonds in all fungal PGs (Centis et al.
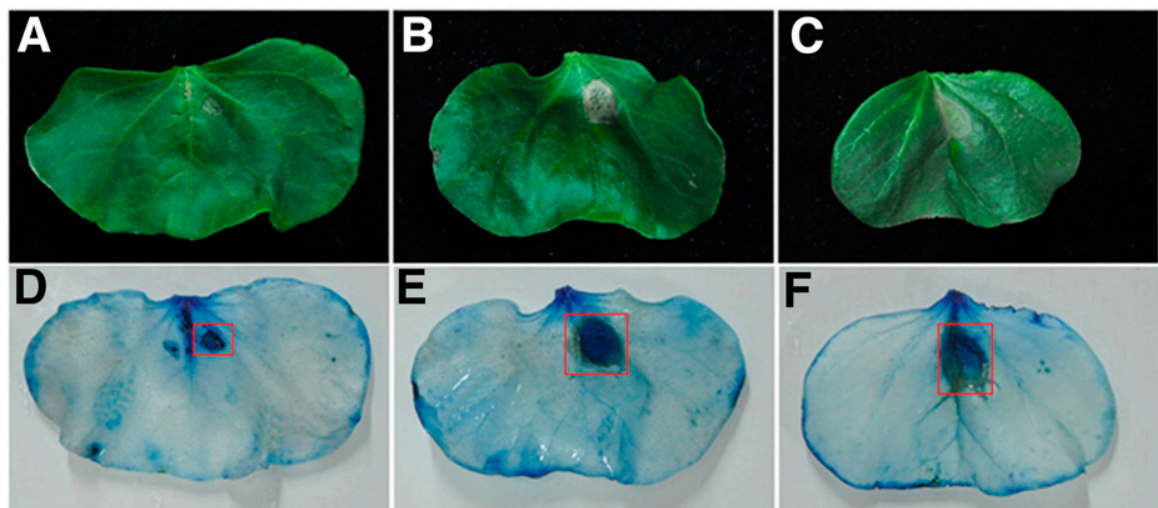

M
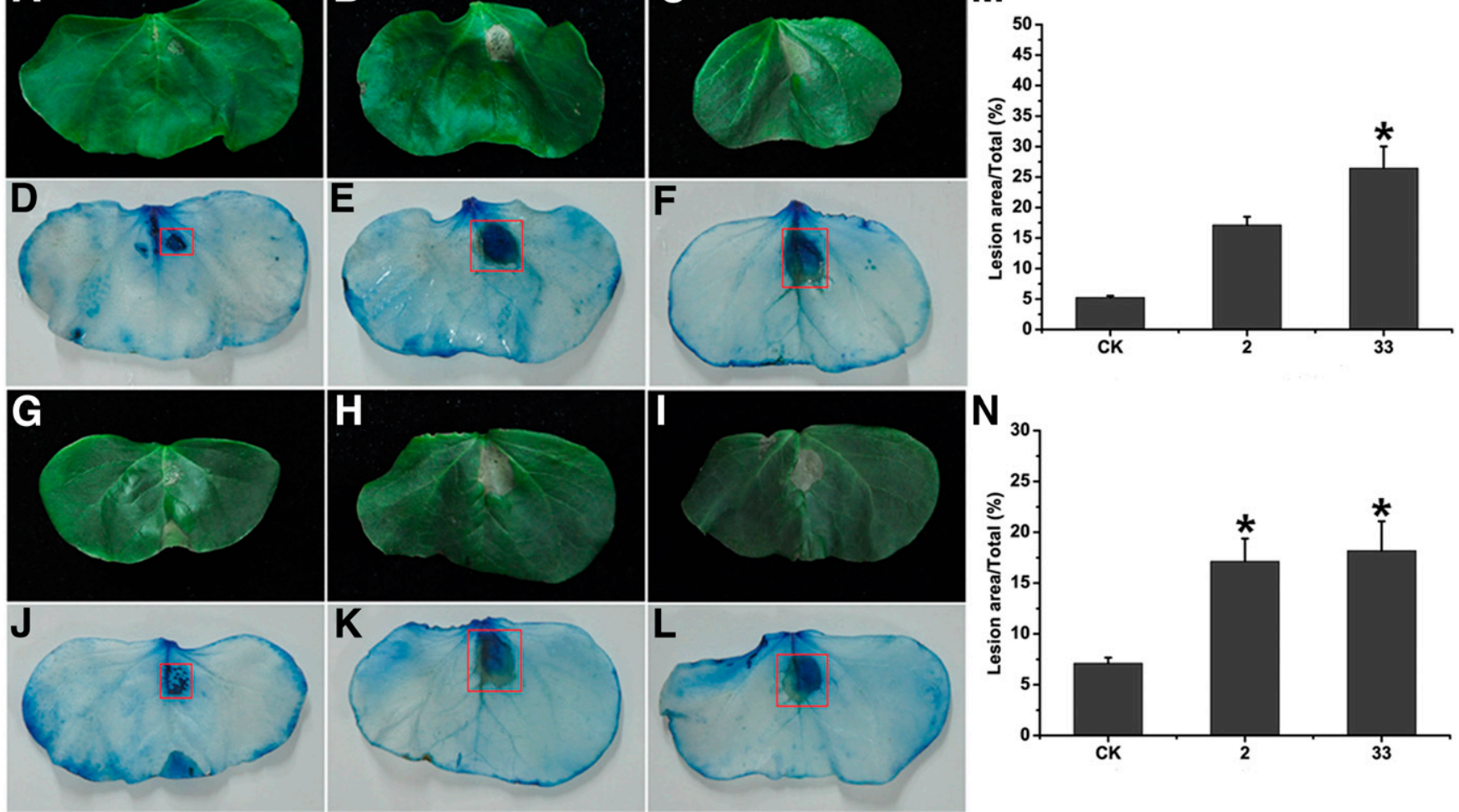

Fig. 7. Necrotizing activity of purified VDPG1 and FOVPG1. A, Control Zhongzhimian 2 leaves inoculated with bacterial lysis buffer, binding buffer, and elution buffer. B, VDPG1 inoculation of Zhongzhimian 2 leaves. C, FOVPG1 inoculation of Zhongzhimian 2 leaves. D, E, and F, Trypan blue staining of A, B, and C. G, Control Xinluzao 33 leaves inoculated with bacterial lysis buffer, binding buffer, and elution buffer. H, VDPG1 inoculation of Xinluzao 33 leaves. I, FOVPG1 inoculation of Xinluzao 33 leaves. J, K, and L, Trypan blue staining of G, H, and I. Leaf necrosis area is indicated by red boxes. M, Disease lesion area in the two cotton cultivars after inoculation with mixed buffer (CK) and VDPG1. N, Disease lesion area in the two cotton cultivars after inoculation with mixed buffer (CK) and FOVPG1. In every experiment, each sample was infiltrated in one section per leaf, two leaves per plant, and assays were performed with at least three plants. Experiments were performed at least thrice with batches of enzymes. The lesion area were means \pm standard errors. All of the data were statistically analyzed. Asterisks indicate a significant difference at $P<0.05$ when compared with control data based on the results of Student's t-test. 
1997). The phylogenetic tree constructed based on the amino acid sequences of VDPG1 and FOVPG1 revealed that VDPG1 was in the same branch as Thielavia arenaria endo-PG, whereas FOVPG1 was in another branch with Fusarium verticillioides 7600 endoPG; homology between PGs within the same branch was $70 \%$ and $93 \%$, respectively (Fig. 2). For most PGs, the optimum $\mathrm{pH}$ ranges between 3.5 and 5.5, although the PGs from Bacillus licheniformis and F. oxysporum f. sp. vasinfectum have an optimal $\mathrm{pH}$ of 11.0 (Di Pietro and Roncero 1996; Prade et al. 1999). The results showed that the optimal pH for VDPG1 was 4.8 and it therefore belongs to the acid pectinases group; however, the optimal $\mathrm{pH}$ for FOVPG1 was 9.0, indicating that this is an alkaline enzyme (Table 1).

PG from some pathogenic fungi such as S. sclerotiorum is expressed in planta during infection of sunflower germlings (Reymond-Cotton et al. 1996). RT-PCR showed that Phytophthora sojae PG1 (PSPG1) expression increased gradually as the duration of infection increased (Sun 2008), whereas the expression of three Rhizoctonia solani AG-IA PGs (RSPGs) showed an early increase followed by a decrease as incubation time progressed (Karimzadeh et al. 2007). Our data revealed that, after inoculation with $V$. dahliae and $F$. oxysporum f. sp. vasinfectum, there was first an increase in VDPG1 and FOVPG1 expression, followed by their decrease in both cotton cultivars, but the expression of the two PGs did not differ significantly between the two cultivars (Fig. 3A and B), suggesting that VDPG1 and FOVPG1 may participate in pathogen penetration through cotton cell wall by degrading pectin and might be closely related to the pathogenicity of these two fungi. Besides, in the further determination of fungal levels in infected cultivars, the susceptible cultivars exhibited a little more accumulated increased fungal biomass when compared with the resistant cultivars in both $V$. dahliae and F. oxysporum f. sp. vasinfectum (Fig. 3C and D); this may be partially reflected in the difference between resistant and susceptible varieties.

Similar to the PGs of most fungi, VDPG1 and FOVPG1 were secreted only in the presence of an inducer (Reymond-Cotton et al. 1996), and similar to Aspergillus flavus PG gene, VDPG1 and FOVPG1 gene expression was induced by pectin but not by glucose. In the pectin medium, both PG genes were expressed during the 8 days of the experiment, whereas in the glucose medium, neither gene was induced (Fig. 4A and B), indicating that both genes have strong substrate specificity.

In plants, hydroxyproline exists mainly in combination with other compounds, such as the cell wall hydroxyproline-rich glycoprotein (HRGP). After pathogen infection, hydroxyproline is accumulated in plants and HRGP increases in plant disease response, suggesting that this is a physiological and biochemical mechanism of induced resistance in plants (Stermer and Hammerschmidt 1987; Ye et al. 1992); a correlation between HRGP accumulation and cell wall lignin has been reported for several species. Hydroxyproline accumulated in cucumber infected by Cladosporium cucumerinum (Hammerschmidt et al. 1984), tomato infected by $F$. oxysporum f. sp. lycopersici (Di Pietro and Roncero 1996), and melon infected by Colletotrichum lagenarium (Ruiz-Avila et al. 1992), and this accumulation was positively correlated with an increase in HRGP. Furthermore, the content of hydroxyproline in resistant muskmelon varieties infected by $C$. lagenarium increased faster than that in susceptible varieties while HRGP increased 10-fold (Esquerré-Tugayé et al. 1979). In the present study, after inoculation with VDPG1 and FOVPG1, hydroxyproline increased in the first 3 days, and there was no significant difference in hydroxyproline content between
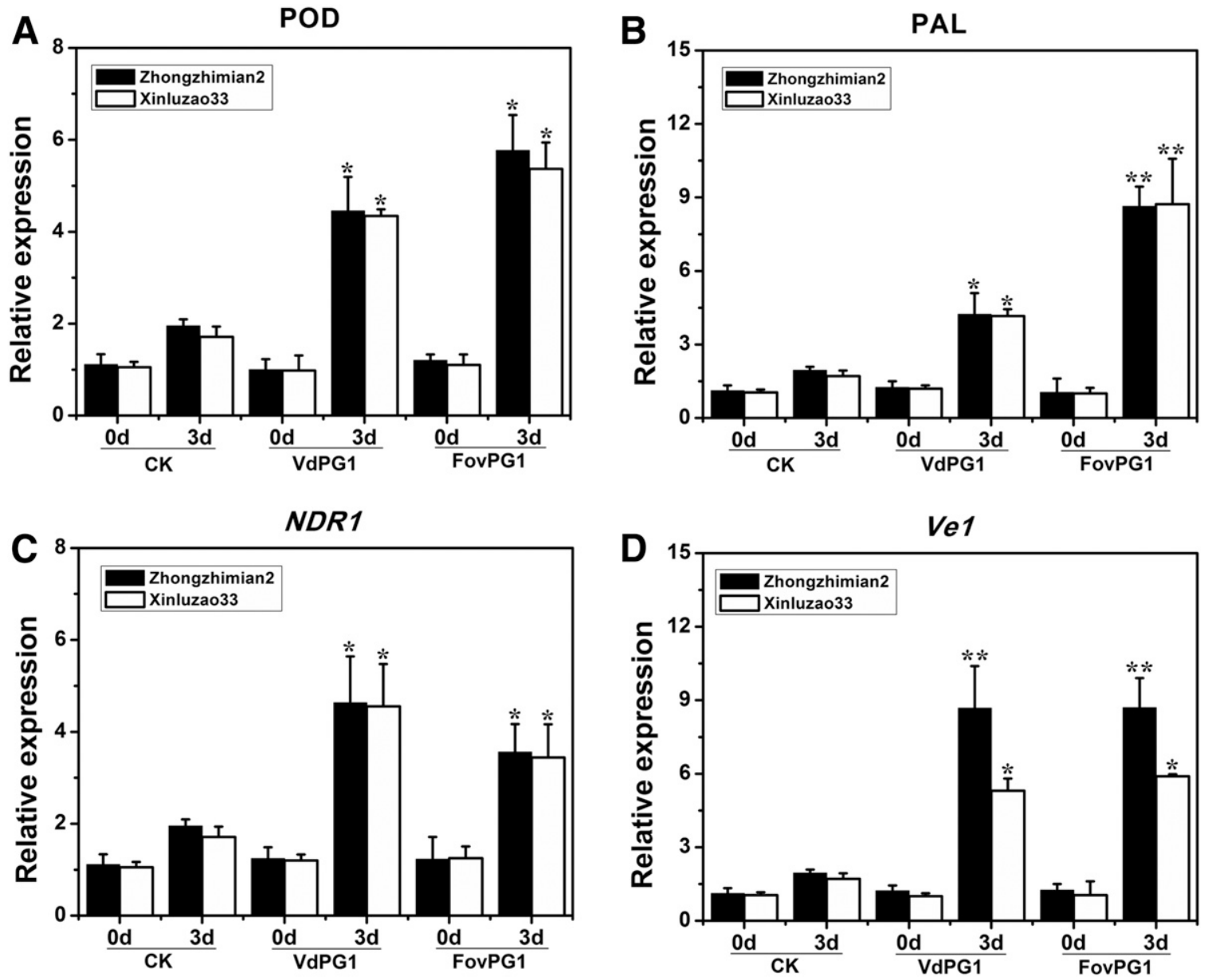

Fig. 8. Expression of host-defense enzymes and genes in cotton cultivars Zhongzhimian 2 and Xinluzao 33 after inoculation with VDPG1 and FOVPG1. A, POD. B, PAL. C, NDR1. $D$, Ve1. Expression on day 0 was used as control. Values were obtained 3 days postinoculation. Data were collected from three independent biological replicates and presented as means \pm standard errors $\left(n=3\right.$ ). Significance of differences between the mean values was analyzed statistically (Student's $t$-test, ${ }^{*} P<0.05,{ }^{* *} P<0.01$ ). 
resistant cultivar and susceptible cultivar (Fig. 6G and $\mathrm{H}$ ). This suggested that accumulation of cell-wall hydroxyproline in cotton seedlings is a resistance mechanism against pathogen infection.

Pectinase is one of the most important virulence factors of plant pathogens and one of the major plant cell-wall-degrading enzymes. Degradation of galactosylated chitosan, a plant cell-wall component, could be due to fungal pectinases, which are considered to play an important role in fungal pathogenicity. Previous studies have shown that A. flavus endo-PG plays an active role in cotton boll infection (Shieh et al. 1997) and that PG is an important virulence factor of ryegrass ergot disease (Oeser et al. 2002). However, the pathogenicity of F. oxysporum f. sp. vasinfectum was not affected after PG1 and PG5 knockout (Di Pietro et al. 1998). Some experimental results showed that fungal endo-PGs release oligogalactose through the plant cell wall, which is crucial to the stimulation of plant defense responses (Cook et al. 1999). To further verify the roles of VDPG1 and FOVPG1 in symptom development in both cotton cultivars, both PGs were inoculated in the stems (Fig. 6A-F) and leaves (Fig. 7) of resistant and susceptible cotton varieties. The extent of damage caused by infiltration of VDPG1 and FOVPG1 appeared similar. Since the plant cell wall is a heterogeneous and dynamic structure, its pectin composition differs among species, tissues, cell types, and regions of the cell wall (Freshour et al. 1996; Kars et al. 2005). Leaf necrosis symptoms may be the consequence of VDPG1 and FOVPG1 action on cell wall integrity leading to tissue collapse and subsequent cell death, although it is difficult to provide a straightforward explanation for this observation.

Plant responses to pathogens are usually classified as either resistant (incompatible interaction) or susceptible (compatible interaction) depending on the ability of plant to limit pathogen growth (Tan et al. 2015). PAL functions as a catalyst for phenylpropanoid metabolism, and its expression and activity in response to environmental stimuli such as $V$. dahlia is revealing of its different patterns of expression (Gayoso et al. 2010). POD is a heme-containing enzyme that catalyzes the oxidation of different substrates using $\mathrm{H}_{2} \mathrm{O}_{2}$ and it is active in physiological processes such as phenol oxidation (Lagrimini 1991) and lignification (Quiroga et al. 2000); these mechanisms may be activated in the defensive response against pathogens (Kristensen et al. 1999). Arabidopsis NDR1 is involved in plant race-specific resistance to infection by bacterial and fungal pathogens (Century et al. 1998; Gao et al. 2011). In tomato, the Vel locus provides resistance against $V$. dahliae (Fradin and Thomma 2006; Gao et al. 2011). Our study demonstrated that PAL, POD, NDR1, and $\mathrm{Vel}$ were upregulated after inoculation with FOVPG1 and VDPG1 (Fig. 8A-D), suggesting that both PGs can stimulate defense and resistance reactions in cotton, possibly through different mechanisms.

In conclusion, the present study characterized the biochemical properties of VDPG1 and FOVPG1, assessed the leaf necrosis caused by the two enzymes in two cotton varieties, and highlighted their potential roles in symptom development in cotton. Observed symptoms in cotton leaves indicated that VDPG1 and FOVPG1 infiltration caused the loss of integrity of the cell wall, leading to tissue collapse and subsequent cell death. Differential expression of host defense enzymes and genes showed that VDPG1 and FOVPG1 might be the elicitors of host defense responses. The role of VDPG1 and FOVPG1 in pathogenicity and virulence on different cotton varieties lays a foundation for studying the interaction mechanisms between cotton and pathogens, allowing a better understanding of the diseases occurring in cotton.

\section{Acknowledgments}

This work was sponsored by the State Key Laboratory of Cotton Biology Open Fund (Grant CB2016B01), by the Genetically Modified Organism Breeding Major Project (Grant 2014ZX08005-002), and by the Program of National Nature Science Foundation of China (Grant 31071751).

\section{Literature Cited}

Afzal, A. J., and Lightfoot, D. A. 2007. Soybean disease resistance protein RHG1-LRR domain expressed, purified and refolded from Escherichia coli inclusion bodies: Preparation for a functional analysis. Protein Expr. Purif. 53:346-355.
Biggs, A. R., El-Kholi, M. M., El-Neshawy, S., and Nickerson, R. 1997. Effects of calcium salts on growth, polygalacturonase activity, and infection of peach fruit by Monilinia fructicola. Plant Dis. 81:399-403.

Borin, M. D. F., Said, S., and Fonseca, M. J. V. 1996. Purification and biochemical characterization of an extracellular endopolygalacturonase from Penicillium frequentans. J. Agric. Food Chem. 44:1616-1620.

Bulantseva, E. A., Tkhang, N. T. E., Buza, N. L., Krinitsyna, A. A., and Protsenko, M. A. 2005. Activity of polygalacturonase-inhibiting protein from banana fruit tissues. Appl. Biochem. Microbiol. 41:251-253.

Carder, J. H., Hignett, R. C., and Swinburne, T. R. 1987. Relationship between the virulence of hop isolates of Verticillium albo-atrum and their in vitro secretion of cell-wall degrading enzymes. Physiol. Mol. Plant Pathol. 31: 441-452.

Centis, S., Guillas, I., Séjalon, N., and Esuerré-Tugayé, M. T. 1997. Endopolygalacturonase genes from Colletotrichum lindemuthianum: Cloning of $C L P G 2$ and comparison of its expression to that of CLPG1 during saprophytic and parasitic growth of the fungus. Mol. Plant-Microbe Interact. 10:769-775.

Century, K. S., Shapiro, A. D., Repetti, P. P., Dahlbeck, D., ., Holub, E., ., and Staskawicz, B. J. 1998. NDR1, a pathogen-induced component required for Arabidopsis disease resistance. Science 278:1963-1965.

Cook, B. J., Clay, R. P., Bergmann, C. W., Albersheim, P., and Darvill, A. G. 1999. Fungal polygalacturonases exhibit different substrate degradation patterns and differ in their susceptibilities to polygalacturonase-inhibiting proteins. Mol. Plant-Microbe Interact. 12:703-711.

Cooke, R. D., Ferber, C. E., and Kanagasabapathy L. 1976. Purification and characterization of polygalaeturonases from a commercial Aspergillus niger preparation. Biochim. Biophys. Acta 452:440-451.

de Vries, R. P., and Visser, J. 2001. Aspergillus enzymes involved in degradation of plant cell wall polysaccharides. Microbiol. Mol. Biol. Rev. 65:497-522.

DellaPenna, D., and Bennett, A. B. 1988. In vitro synthesis and processing of tomato fruit polygalacturonase. Plant Physiol. 86:1057-1063.

Di Pietro, A., García-Maceira, F. I., Huertas-González, M. D., Ruíz-Roldan, M. C., Caracuel, Z., Barbieri, A. S., and Mig, R. 1998. Endopolygalacturonase PG1 in different formae speciales of Fusarium oxysporum. Appl. Environ. Microbiol. 64:1967-1971.

Di Pietro, A., and Roncero, M. I. G. 1996. Purification and characterization of an exo-polygalacturonase from the tomato vascular wilt pathogen Fusarium oxysporum f. sp. lycopersici. Physiol. Mol. Plant Pathol. 49:177-185.

Dowd, C., Wilson, L. W., and Mcfadden, H. 2004. Gene expression profile changes in cotton root and hypocotyl tissues in response to infection with Fusarium oxysporum f. sp vasinfectum. Mol. Plant-Microbe Interact. 17: 654-667.

Dumas, B. S., Sarrazin, N., and Esquerre Tugaye, M. T. 1999. Use of green fluorescent protein to detect expression of an endopolygalacturonase gene of Colletotrichum lindemuthianum during bean infection. Appl. Environ. Microbiol. 65:1769-1771.

Ellendorff, U., Fradin, E. F., Jonge, R. D., and Thomma, B. P. H. J. 2009. Rna silencing is required for Arabidopsis defence against Verticillium wilt disease. J. Exp. Bot. 60:591-602.

Esquerré-Tugayé, M. T., Lafitte, C., Mazau, D., Toppan, A., and Touzé, A. 1979. Cell surfaces in plant-microorganism interactions: II. Evidence for the accumulation of hydroxyproline-rich glycoproteins in the cell wall of diseased plants as a defense mechanism. Plant Physiol. 64:320-326.

Fradin, E. F., Abd-El-Haliem, A., Masini, L., van den Berg, G. C. M., Joosten M. H. A. J., and Thomma, B. P. H. J. 2011. Interfamily transfer of tomato ve1 mediates Verticillium resistance in Arabidopsis. Plant Physiol. 156:2255-2265.

Fradin, E. F., and Thomma, B. P. H. J. 2006. Physiology and molecular aspects of verticillium wilt diseases caused by Verticillium dahlia and Verticillium alboatrum. Mol. Plant Pathol. 7:71-86.

Fraissinet-Tachet, L., and Reymond, C. P. M. 1995. Characterization of a multigene family encoding an endopolygalacturonase in Sclerotinia sclerotiorum. Curr. Genet. 29:96-99.

Freshour, G., Clay, R. P., Fuller, M. S., Albersheim, P., Darvill, A. G., and Hahn, M. G. 1996. Developmental and tissue-specific structural alterations of the cell-wall polysaccharides of Arabidopsis thaliana roots. Plant Physiol. 110:1413-1429.

Gao, S. J., Choi, G. L., and Nuss, D. L. 1996. Cloning and targeted disruption of ENPG-1, encoding the major in vitro extracellular endopolygalacturonase of the chestnut blight fungus, Cryphonectria parasitica. Appl. Environ. Microbiol. 62:1984-1990.

Gao, X. Q., Terry, W., Zhaohu, L., Kenerley, C. M., Ping, H., and Libo, S. 2011. Silencing GhNDR1 and GhMKK2 compromises cotton resistance to Verticillium wilt. Plant J. 66:293-305.

Gayoso, C., Pomar, F., Novo-Uzal, E., Merino, F., and de Ilárduya, Ó. M. 2010 The Ve-mediated resistance response of the tomato Verticillium dahliae involves $\mathrm{H} 2 \mathrm{O} 2$, peroxidase and lignins and drives PAL gene expression. BMC Plant Biol. 10:232.

Götesson, A., Marshall, J. S., Jones, D. A., and Hardham, A. R. 2002 Characterization and evolutionary analysis of a large polygalacturonase gene family in the oomycete plant pathogen Phytophthora cinnamomi. Mol. PlantMicrobe Interact. 15:907-921.

Hammerschmidt, R., Lamport, D. T. A., and Muldoon, E. P. 1984. Cell wall hydroxyproline enhancement and lignin deposition as an early event in the 
resistance of cucumber to Cladosporium cucumerinum. Physiol. Plant Pathol. 24:43-47.

Heale, J. B. 1988. Verticillium spp., the cause of vascular wilts in many species. Adv. Plant Pathol. 6:291-312.

James, J. T., and Dubery, I. A. 2001. Inhibition of polygalacturonase from Verticillium dahliae, by a polygalacturonase inhibiting protein from cotton. Phytochemistry 57:149-156.

Karimzadeh, F., Motallebi, M., Zamani, M. R., and Hamze, S. 2007. Determination of culture condition for polygalacturonase production by Rhizoctonia solani ag2-2, causal agent of root rot in sugar beet. Plant Pathol. J. 6:153-158.

Kars, I., Krooshof, G. H., Wagemakers, L., Joosten, R. A. E., Benen, J., and Kan, J. A. 2005. Necrotizing activity of five Botrytis cinerea endopolygalacturonases produced in Pichia pastoris. Plant J. 43:213-225.

Kivirikko, K. I., and Liesmaa, M. 2009. A colorimetric method for determination of hydroxyproline in tissue hydrolysates. Scand. J. Clin. Lab. Invest. 11:128-133.

Kristensen, B. K., Bloch, H., and Rasmussen, S. K. 1999. Barley coleoptile peroxidases. Purification, molecular cloning, and induction by pathogens. Plant Physiol. 120:501-512.

Lagrimini, L. M. 1991. Wound-induced deposition of polyphenols in transgenic plants overexpressing peroxidase. Plant Physiol. 96:577-583.

Li, R., Rimmer, R., Buchwaldt, L., Sharpe, A. G., Séguin-Swartz, G., and Hegedus, D. D. 2004. Interaction of Selerotinia sclerotiorum with Brassica napus: Cloning and characterization of endo- and exo-polygalacturonases expressed during saprophytic and parasitic modes. Fungal Genet. Biol. 41:754-765.

Liang, Y., Yu, Y., Shen, X., Dong, H., Lyu, M., Xu, L., Ma, Z., Liu, T., and Cao, J. 2015. Dissecting the complex molecular evolution and expression of polygalacturonase gene family in brassica rapa ssp. chinensis. Plant Mol. Biol. 89:629-646.

Liu, N. N., Ma, X. W., Zhou, S. H., Wang, P., Sun, Y., Li, X. N., and Hou, Y. X. 2016. Molecular and functional characterization of a polygalacturonaseinhibiting protein from Cynanchum komarovii that confers fungal resistance in Arabidopsis. PLoS One 11:e0146959.

Maceira, F. I. G. A., Pietro, A. D., and Roncero, M. I. G. 1997. Purification and characterization of a novel exopolygalacturonase from Fusarium oxysporum f. sp. lycopersici. FEMS Microbiol. Lett. 154:37-43.

Markovič, O., and Janeček, S. 2001. Pectin degrading glycoside hydrolases of family 28: Sequence-structural features, specificities and evolution. Protein Eng. 14:615-631.

Moerschbacher, B. M., Noll, U. M., Flott, B. E., and Reisener, H. J. 1988. Lignin biosynthetic enzymes in stem rust infected, resistant and susceptible nearisogenic wheat lines. Physiol. Mol. Plant Pathol. 33:33-46.

Oeser, B., Heidrich, P. M., Müller, U., Tudzynski, P., and Tenberge, K. B. 2002. Polygalacturonase is a pathogenicity factor in the Claviceps purpurea /rye interaction. Fungal Genet. Biol. 36:176-186.

Prade, R. A., Zhan, D., Ayoubi, P., and Mort, A. J. 1999. Pectins, pectinases, and plant-microbe interactions. Biotechnol. Genet. Eng 16:361-392.

Puhalla, J. E., and Howell, C. R. 1975. Significance of endo-polygalacturonase activity to symptom expression of verticillium wilt in cotton, assessed by the use of mutants of verticillium dahliae, kleb. Physiol. Plant Pathol. 7:147-150.

Quiroga, M., Guerrero, C., Botella, M. A., Barceló, A., Amaya, I., Medina, M. I., Alonso, F. J., de Forchetti, S. M., Tigier, H., and Valpuesta, V. 2000. A tomato peroxidase involved in the synthesis of lignin and suberin. Plant Physiol. 122: 1119-1128.

Reymond-Cotton, P., Fraissinet-Tachet, L., and Fèvre, M. 1996. Expression of the Sclerotinia sclerotiorum polygalacturonase PG1 gene - possible involvement of CREA in glucose catabolite repression. Curr. Genet. 30:240-245.
Ruiz, G. B., Pietro, A. D., and Roncero, M. I. G. 2016. Combined action of the major secreted exo- and endopolygalacturonases is required for full virulence of Fusarium oxysporum. Mol. Plant Pathol. 17:339-353.

Ruiz-Avila, L., Burgess, S. R., Stiefel, V., Ludevid, M. D., and Puigdomènech, P. 1992. Accumulation of cell wall hydroxyproline-rich glycoprotein mRNA is an early event in maize embryo cell differentiation. P. Natl. Acad. Sci. Usa. 89: $2414-2418$

Sal'Kova, E. G., and Guseva, N. N. 1965. The role of pectolytic enzymes of the Verticillium dahliae fungus in the development of cotton wilt. Dokl. Akad. Nauk SSSR 163:515-522

Shieh, M. T., Brown, R. L., Whitehead, M. P., Cary, J. W., Cotty, P. J., Cleveland, T. E., and Dean, R. A. 1997. Molecular genetic evidence for the involvement of a specific polygalacturonase, $\mathrm{P} 2 \mathrm{c}$, in the invasion and spread of Aspergillus flavus in cotton bolls. Appl. Environ. Microbiol. 63:3548-3552.

Stermer, B. A., and Hammerschmidt, R. 1987. Association of heat shock induced resistance to disease with increased accumulation of insoluble extensin and ethylene synthesis. Physiol. Mol. Plant Pathol. 31:453-461.

Sun, W. X. 2008. Effect of activities of polygalacturonase on pathogenicity in Phytophthora sojae. Mod. Agric. Sci. 15:42-43.

Tan, G., Liu, K., Kang, J., Xu, K., Zhang, Y., Hu, L., et al. 2015. Transcriptome analysis of the compatible interaction of tomato with Verticillium dahliae using RNA-sequencing. Front. Plant Sci. 6:428.

Taylor, R. J., and Secor, G. A. 1988. An improved diffusion assay for quantifying polygalacturonase content of Erwinia culture filtrates. Phytopathology 78 1101-1103.

Wang, Q. H., Li, F. G., Zhang, X., Zhang, Y. A., Hou, Y. X., Zhang, S. R., and Wu, Z. X. 2011. Purification and characterization of a CkTLP protein from Cynanchum komarovii seeds that confers antifungal activity. PLoS One 6:e16930.

Wang, X., Zhu, X., Tooley, P., and Zhang, X. 2013. Cloning and functional analysis of three genes encoding polygalacturonase-inhibiting proteins from Capsicum annuum and transgenic CaPGIP1 in tobacco in relation to increased resistance to two fungal pathogens. Plant Mol. Biol. 81:379-400.

Yang, B., Yajima, W., Das, D., Suresh, M. R., and Kav, N. N. V. 2009. Isolation, expression and characterization of two single-chain variable fragment antibodies against an endo-polygalacturonase secreted by Sclerotinia sclerotiorum. Protein Expr. Purif. 64:237-243

Ye, X. S., Järlfors, U., Tuzun, S., Pan, S. Q., Kuc, J., Ye, X. S., Järlfors, U., Tuzun, S., and Kuc, J. 1992. Biochemical changes in cell walls and cellular responses of tobacco leaves related to systemic resistance to blue mold (Peronospora tabacina) induced by tobacco mosaic virus. Can. J. Bot. 70:49-57.

Zambounis, A. G., Paplomatas, E., and Tsaftaris, A. S. 2007. Intergenic spacer-RFLP analysis and direct quantification of Australian Fusarium oxysporum f. sp. vasinfectum isolates from soil and infected cotton tissues. Plant Dis. 91:1564-1573.

Zhang, J., Bruton, B. D., and Biles, C. L. 1999. Fusarium solani endopolygalacturonase from decayed muskmelon fruit: Purification and characterization. Physiol. Mol. Plant Pathol. 54:171-186.

Zhang, Y., Wang, Q., Zhang, X., Liu, X., Wang, P., and Hou, Y. 2011. Cloning and characterization of an annexin gene from Cynanchum komarovii that enhances tolerance to drought and Fusarium oxysporum in transgenic cotton. J. Plant Biol. 54:303-313.

Zhu, Y. F., Schluttenhoffer, C. M., Pengcheng, W., Fuyou, F., Jyothi, T., JianKang, Z., Yeol, L. S., Dae-Jin, Y., and Tesfaye, M. 2014. Cyclin-dependent kinase 8 differentially regulates plant immunity to fungal pathogens through kinase-dependent and -independent functions in Arabidopsis. Plant Cell 26: $4149-4170$ 